九州大学学術情報リポジトリ

Kyushu University Institutional Repository

\title{
Evaluation of Sugi Finger-jointed Laminae with a Knot and Starved Joints by Acoustic Emission
}

Yano, Kiyoko

Faculty of Agriculture, Kyushu University

Ouchi, Takeshi

Faculty of Agriculture, Kyushu University

Murase, Yasuhide

Faculty of Agriculture, Kyushu University

Fujimoto, Yoshiyasu

Miyazaki Prefectural Wood Utilization Research Center

他

https://doi.org/10.5109/9291

出版情報：九州大学大学院農学研究院紀要. 52 (1)，pp.111-116，2007-02-28. Faculty of Agriculture, Kyushu University

バージョン：

権利関係 : 


\title{
Evaluation of Sugi Finger-jointed Laminae with a Knot and Starved Joints by Acoustic Emission
}

\author{
Kiyoko YANO ${ }^{1}$, Takeshi OHUCHI*, Yasuhide MURASE, \\ Yoshiyasu FUJIMOTO ${ }^{2}$, and Hideki MORITA ${ }^{2}$
}

\author{
Laboratory of Wood Material Technology, Division of Biomaterial Science, Department of Forest and \\ Forest Products Sciences, Faculty of Agriculture, Kyushu University, \\ Fukuoka 812-8581, Japanese \\ (Received November 10, 2006 and accepted December 1, 2006)
}

\begin{abstract}
In the manufacture of glulam timbers, the laminae that have knots near the finger-joint and starved part in the finger-joint are often found, and it will greatly influence the decrease in strength of products. Therefore, the detection of knots and starved joints is important for preparation of laminae, and the method is hoped to be simple and non-destructive. In this study, sugi (Cryptomeria japonica D. Don) finger-jointed laminae with an intergrown knot near the finger-joint and starved joints in the finger-joint were prepared, and the evaluation of finger-joint performance was conducted by acoustic emission (AE) as the non-destructive method. That is, bending tests for these laminae were performed, and AE generated during bending test was measured along with load. Then, the correspondence between $\mathrm{AE}$ characteristics and the strength properties was examined. The main results are summarized as follows: for the laminae with a knot parallel to the finger-joint and starved joints in the finger-joints, AE signals were measured at the early stage of the bending test and the accumulated $\mathrm{AE}$ count was large as compared with the laminae without knots and starved joints/controls. Therefore, the AE technique is promising for the monitoring of knots and starved joints during bending test. In this experiment, for the laminae with a knot, the difference of the bending strength was not admitted. From this result, the bending strength was almost unaffected by the difference of the knot position near finger-joint. For the laminae with starved-joints, the MOE was almost unaffected by the presence of the starved joints, while the MOR decreased slightly as compared with the controls. It follows from the above results that the $\mathrm{AE}$ technique is promising for the detection of knot parallel to the finger-joint and starved joints in the finger-joint at the early stage of the bending test, even if the knot and starved joints do not cause much reduction in the bending strength.
\end{abstract}

\section{INTRODUCTION}

Recently, many large-scale wooden buildings made of sugi heavy glulam timbers have been constructed in Japan. To guarantee the strength properties of these timbers, a high level of quality control is needed. The laminae that comprise glulam timber are generally finger-jointed. However, laminae with konts near the finger-joint and starved joints in the finger-joint are often found in the manufacture of glulam timbers, and greatly decrease the timbers' strength when located on the external layer. Therefore, for the manufacture of glulam timbers with good strength properties, the evaluation of finger-joint properties after finger-jointing is important, and the method is hoped to be simple and non-destructive. In a previous study on the evaluation of performance for wood based-materials by the non-destructive method, the detection of starved joints in plywood by acoustic emission (AE) was investigated (Yoshimura et al., 1987). For butt-jointed laminae, bending test has been performed and $\mathrm{AE}$ generated during bending test has also been investigated (Byeon et

\footnotetext{
${ }^{1}$ Laboratory of Wood Material Technology, Division of Biomaterial Science, Department of Forest and Forest Products Sciences, Faculty of Agriculture, Kyushu University, Japanese.

${ }^{2}$ Miyazaki Prefectural Wood Utilization Research Center, 8850037 Miyakonojo, Japan

* Corresponding author (E-mail: tohuchi@agr.kyushu-u.ac.jp)
}

$a l ., 1992)$. In addition, other studies have been conducted in the past (Arakawa et al., 2001; Xu Y et al., 1993). However, the evaluation of performance for finger-jointed laminae in actual size by the non-destructive method has not been examined.

In this study, sugi (Cryptomeria japonica D. Don) finger-jointed laminae with an intergrown knot near the finger-joint and starved joints in the finger-joint were prepared, and the evaluation of finger-joint performance was conducted by $\mathrm{AE}$ as the non-destructive method. That is, bending tests for these laminae were performed, and $\mathrm{AE}$ generated during bending test was measured along with the load. Then, AE characteristics and bending strength properties were examined.

\section{MATERIALS AND METHODS}

\section{Specimens}

Specimens used in this study were made with sugi (Cryptomeria japonica D. Don) laminae. Their modulus of elasticity (MOE) ranged from 8 to $9 \mathrm{kN} / \mathrm{mm}^{2}$. The specific gravities and the moisture contents of specimens were around 0.42 and $10.9 \%$, respectively. These laminae were sorted according to whether or not they had any knots within $200 \mathrm{~mm}$ of the tip of the finger. Short-length laminae were made in the following conditions. These laminae were finger-jointed using resorcinol phenol resin type adhesive (SR-160) and end pressed at $4.6 \mathrm{~N} / \mathrm{mm}^{2}$. The adhesive was double spread on the laminae before pressing, and the specimens were 
cured at room temperature for more than 48 hours after adhesion. The profile of the finger-joint was as shown in Fig. 1, where $\mathrm{L}=25.0 \mathrm{~mm}, \mathrm{p}=6.0 \mathrm{~mm}, \mathrm{t} 1=0.8 \mathrm{~mm}$, $\mathrm{t} 2=0.6 \mathrm{~mm}$, and $\theta=5$ in 29 . The laminae without knots and starved joints were used as control specimens. The bending specimens were $144 \mathrm{~mm}$ wide, $30 \mathrm{~mm}$ thick, and $1000 \mathrm{~mm}$ long.

Laminae with an intergrowth knot

Laminae with knots had one intergrowth knot about

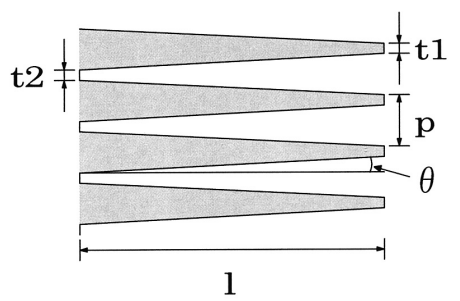

Fig. 1. Profile of the finger-joint.

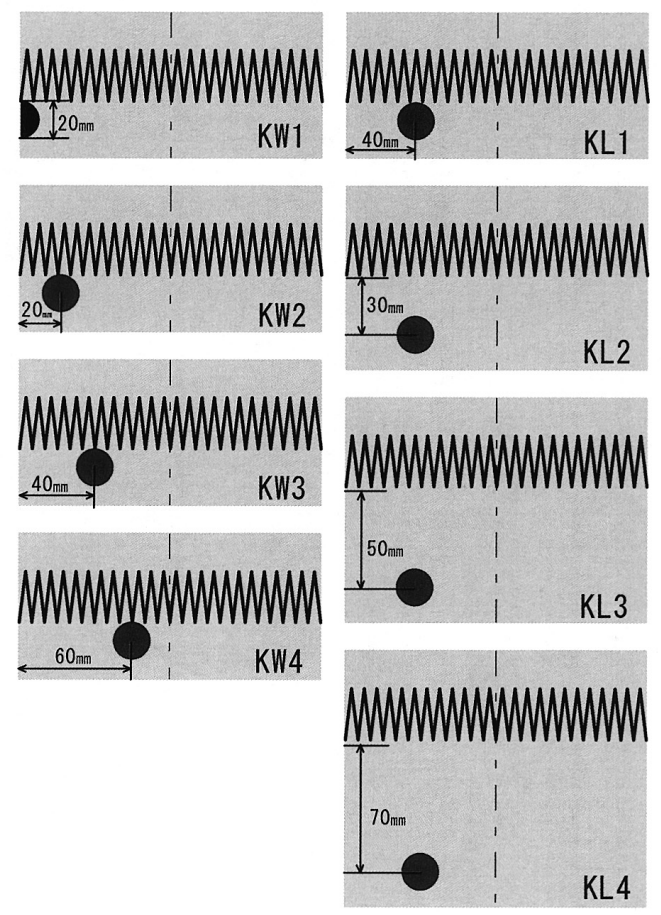

Fig. 2. Types of specimens with a knot.
$20 \mathrm{~mm}$ in diameter near the finger-joint. Laminae with a knot within $20 \mathrm{~mm}$ of the tip of the finger-joint and parallel to the finger-joint were described as KW; those with a knot within $40 \mathrm{~mm}$ of the edge of the specimen in the length direction were described as KL. KW and KL knot positions were set as shown in Fig. 2 and assumed to be KW1-4 and KL1-4, respectively.

\section{Laminae with starved joints}

Laminae with starved joints in the finger-joint have no knots within $200 \mathrm{~mm}$ of the tip of the finger-joint. These laminae, upon which adhesive was not spread on one of 24 fingers parallel to the width (starved joint), were described as $1 \mathrm{~N}$; those with two starved joints were $2 \mathrm{~N}$, and those with three starved joints were $3 \mathrm{~N}$. These positions of starved joints were set as shown in Fig. 3 and assumed to be s, q, and c, respectively.

\section{AE monitoring method during bending test}

Figure 4 shows a schematic diagram of the bending test and AE measurement. A static bending test for all specimens was conducted by four-point loading using the Instron mode strength test machine. The span was $630 \mathrm{~mm}$, the distance between the loading point and supporter was $210 \mathrm{~mm}$, and the crosshead speed was set at $5.0 \mathrm{~mm} / \mathrm{min}$. The MOE and modulus of rupture (MOR) were measured and recorded for each specimen. In addition, the $\mathrm{AE}$ generations during the bending test were measured along with load. Two AE-sensors (901S: NF) were mounted on each side of the finger-joint using electron wax as a couplant. The AE signal received by the $\mathrm{AE}$ sensors during the bending tests was amplified to $40 \mathrm{~dB}$ by a preamplifier (9917: NF) and additionally amplified to $40 \mathrm{~dB}$ by a main amplifier (7691: NF). The threshold level was $20 \mathrm{mV}$.

\section{RESULTS AND DISCUSSION}

\section{Accumulated AE count}

Figure 5 shows the relationship between the accumulated AE count and the load for each KW specimen, and the control. For each KW specimen, AE signals were measured at the early stage of the bending test and the accumulated AE count was large as compared with the laminae without knot/control. This was considered
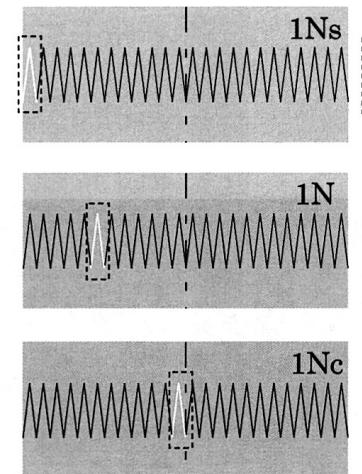
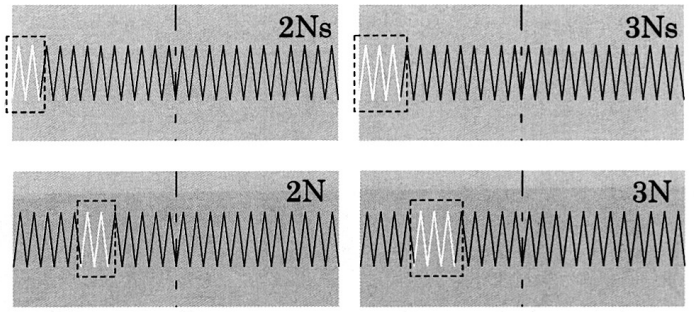

$2 \mathrm{Nc}$
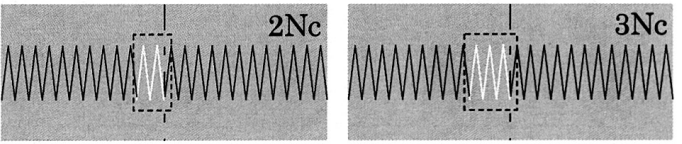

Fig. 3. Types of specimens with starved joints. 
that the slight destruction was caused by a knot near the finger-joint. However, the difference in accumulated $\mathrm{AE}$ count between each $\mathrm{KL}$ specimen and control was not admitted.
Figure 6 shows the relationship between the accumulated $\mathrm{AE}$ count and the load for $1 \mathrm{Ns}, 2 \mathrm{Ns}, 3 \mathrm{Ns}$, and the control. It was found that AE signals of laminae with starved joints occurred comparatively early in the bend-

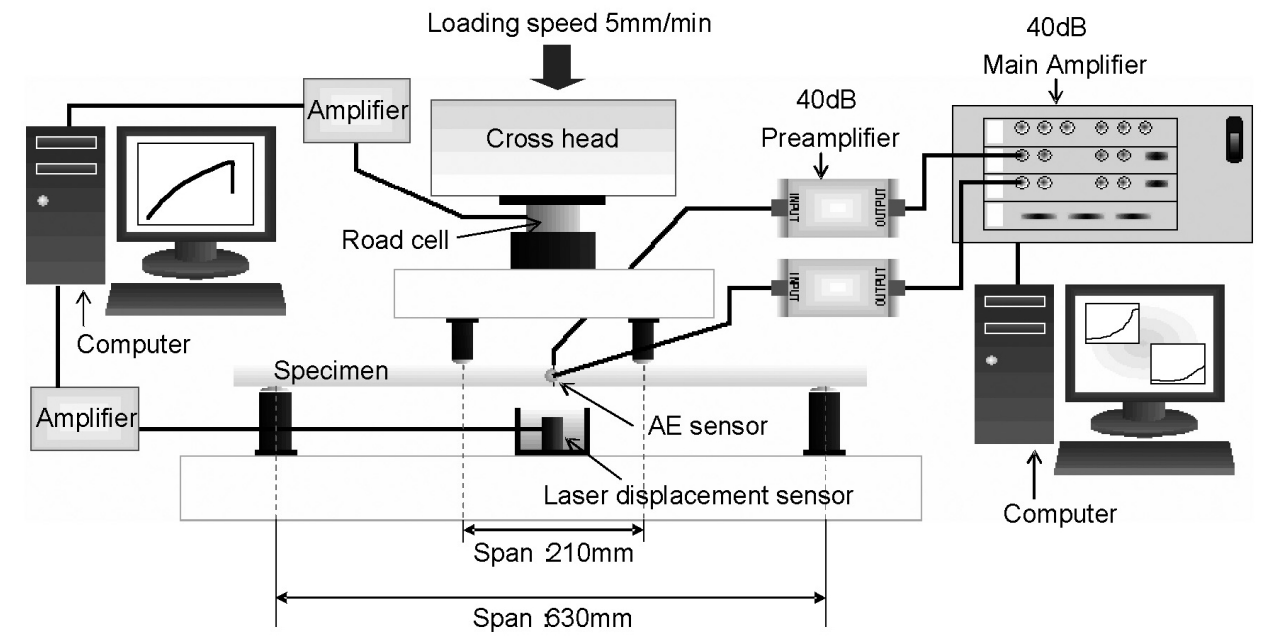

Fig. 4. Schematic diagram of bending test and AE measurement.

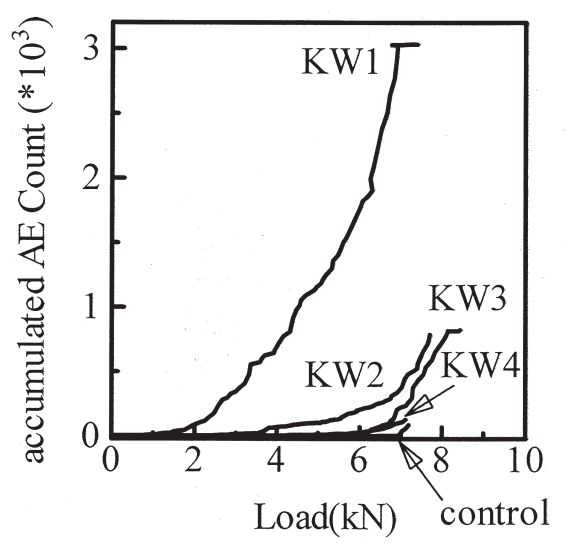

Fig. 5. Relationship between accumulated AE count and load.

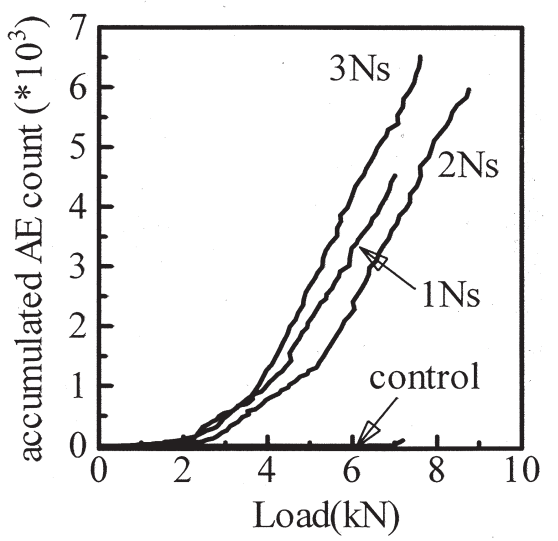

Fig. 6. Relationship between accumulated AE count and load.
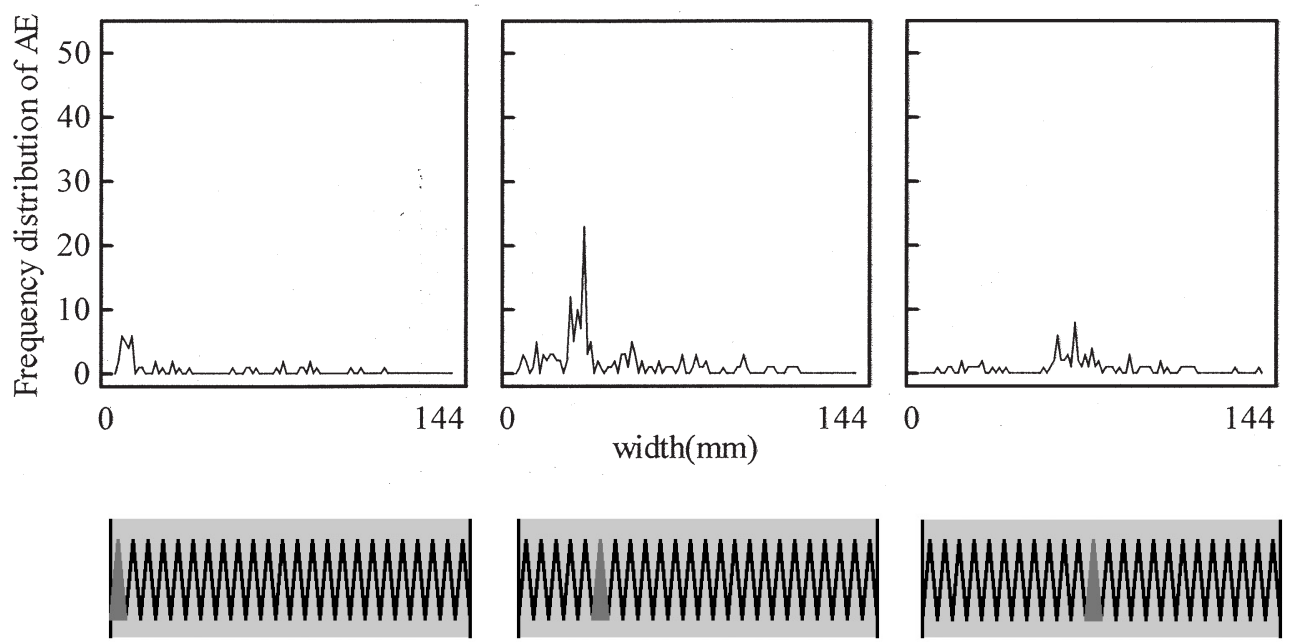

Fig. 7. Detection results of one-dimensional AE source positioning for $1 \mathrm{~N}$ type. 
ing test, and the accumulated $\mathrm{AE}$ counts for these laminae were also much larger than those of the controls.

In addition, for laminae with starved joints, $\mathrm{AE}$ source position was detected by the one-dimensional method. Figure $\mathbf{7}$ shows the detection results of one-dimensional AE source positioning for $1 \mathrm{~N}$ type. The pictures of finger-joints in the lower half of Fig. 7 correspond to the width of the abscissas in the upper half of Fig. 7, and the gray part of the finger-joint shows the starved joint. As is made clear in this figure, the $\mathrm{AE}$ peak coincided with the starved joints part. Similar tendencies were shown in $2 \mathrm{~N}$ and $3 \mathrm{~N}$ types. From the observation of the specimens after the bending test, we concluded that most of the laminae had gaps at the starved joints part, and cracks occurred as shown in Fig.
8. These results suggested that $\mathrm{AE}$ was generated at the starved joints.

\section{AE generation load}

The load when AE generation started is designated the "AE generation load". Figures 9 and $\mathbf{1 0}$ show the relationship between the $\mathrm{AE}$ generation load and each specimen. The AE generation load for each KW specimen increased as the distance between $\mathrm{AE}$ sensor and knot increased, and the loads were small as compared with those of controls. In KL specimens, the difference of the AE generation load caused by the difference of the knot positions was not admitted, and the difference of that was not also admitted between KL specimen and controls.
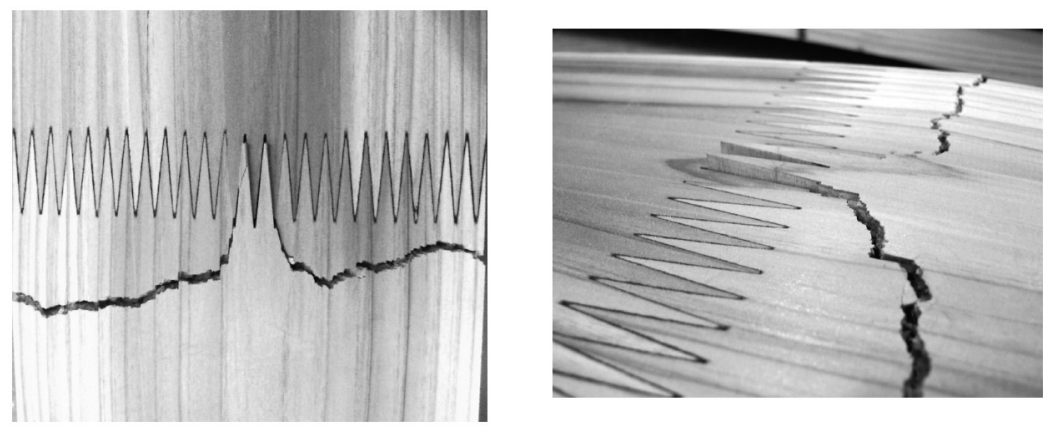

Fig. 8. Cracks and gaps of specimens with starved joints for 3Nc type.

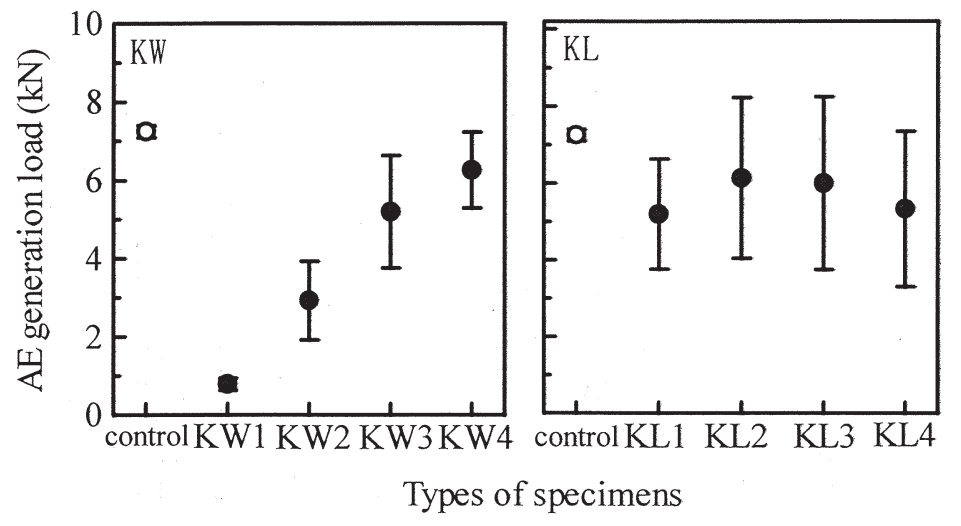

Fig. 9. Relationship between $\mathrm{AE}$ generation load and each specimen with a knot.
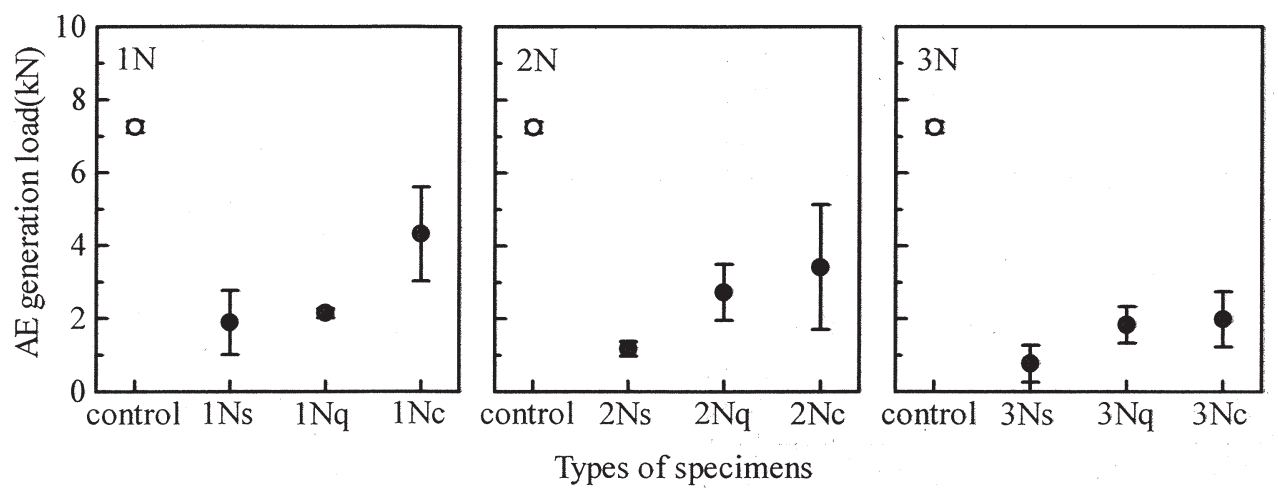

Fig. 10. Relationship between AE generation load and each specimen with starved joints. 
The AE generation load for $\mathrm{N}$ specimens increased as the distance between $\mathrm{AE}$ sensor and starved joints increased. This is probably because the AE signal level decreased as the distance between the $\mathrm{AE}$ sensor and the starved joint increased, due to $\mathrm{AE}$ attenuation. In addition, the $\mathrm{AE}$ generation load of all laminae with starved joints was lower than that of controls during the bending test.

These results all suggested that the $\mathrm{AE}$ technique is promising for the detection of both knot parallel to the finger-joint and starved joints in the finger-joint at the early stage of the bending test.

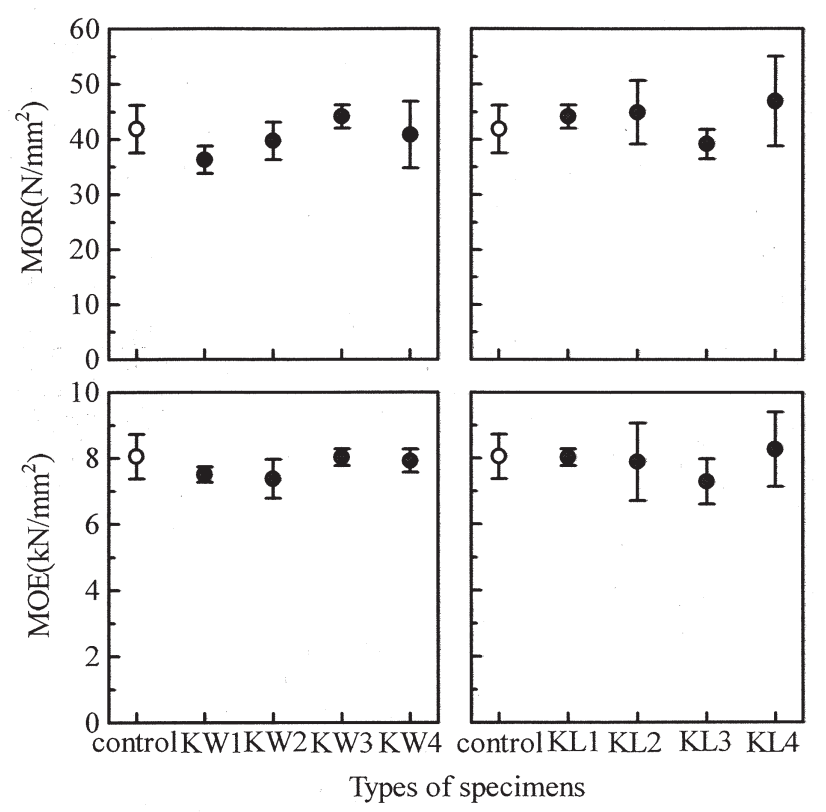

Fig. 11. Relationship between MOR and MOE and each KW and KL specimen with a knot.

\section{Bending strength properties}

Figure 11 shows the relationship between MOR and MOE and each KW and KL specimen. No difference of the bending strength between KW or KL specimens and controls was admitted. From this result, the bending strength was almost unaffected by the difference of the knot position near the finger-joint. It follows from the above results that the slight destruction caused by knot does not greatly influence the decrease in strength properties of laminae.

Figure 12 shows the relationship between MOR and MOE and each N specimen. There was no effect of starved joints on MOR for any of the $1 \mathrm{~N}$ types. However, the MOR of $2 \mathrm{Nq}, 2 \mathrm{Nc}$, and all $3 \mathrm{~N}$ types decreased slightly as compared with that of the laminae without starved joints/controls. These results suggested that the $\mathrm{AE}$ technique is promising for the estimation of strength degradation of laminae with starved joints of $2 \mathrm{~N}$ and $3 \mathrm{~N}$ types. On the other hand, MOE was almost unaffected by the starved joints.

\section{CONCLUSIONS}

In this study, sugi finger-jointed laminae with a knot and starved joints were prepared, respectively, and the evaluation of performance for finger-joints was conducted by acoustic emission (AE). That is, bending tests for these laminae were performed, and $\mathrm{AE}$ generated during the bending test was measured along with the load. Then, AE characteristics and bending strength properties of these laminae were examined. The main results are summarized as follows:

1. For the laminae with a knot parallel to the finger-joint and starved joints in the finger-joints, AE signals were measured at a comparatively early stage

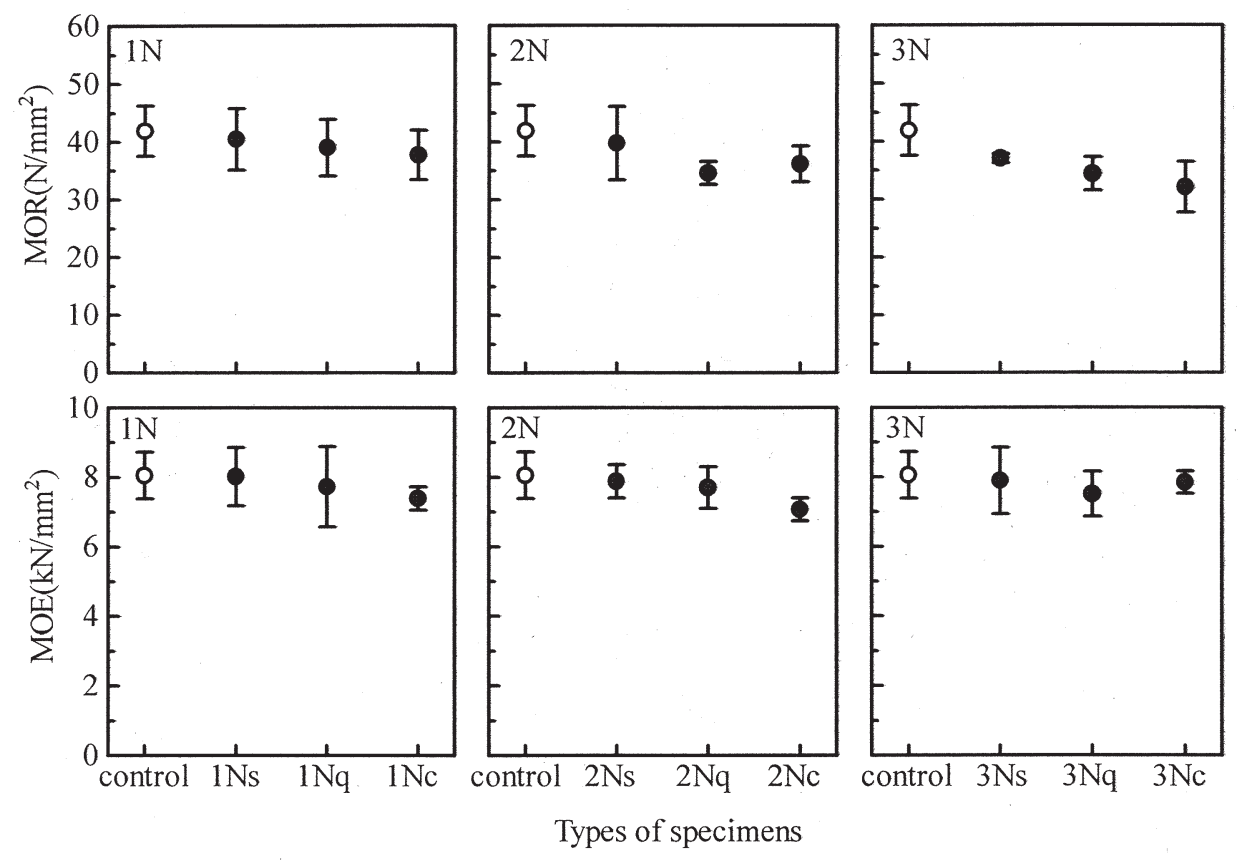

Fig. 12. Relationship between $M O R$ and MOE and each $N$ specimen with starved joints. 
of the bending test, and the accumulated AE counts were very large as compared with the laminae without knots and starved joints/controls.

2. From the detection results of one-dimensional AE source positioning for laminae with starved joints, it was confirmed that $\mathrm{AE}$ was generated at the starved part of the finger-joint.

3. The AE generation load for the laminae with a knot parallel to the finger-joint increased as the distance between AE sensor and knot increased, and these loads were small as compared with that of the controls. The AE generation load for the laminae with starved joints increased as the distance between AE sensor and starved joints increased. In addition, the $\mathrm{AE}$ generation load of all laminae with starved joints was lower than that of controls during the bending test.

4. The difference of the bending strength between all laminae with a knot and controls was not admitted. From this result, the bending strength was almost unaffected by the difference of the knot position. For the laminae with starved-joints, the MOE was almost unaffected by the presence of the starved joints, while the MOR decreased slightly as compared with the controls.

It follows from the above results that the $\mathrm{AE}$ technique is promising for the detection of knot parallel to the finger-joint and starved joints in the finger-joint at the early stage of the bending test, even if the knot and starved joints do not cause much reduction in the bending strength.

\section{REFERENCES}

Ayarkwa J, Hirashima Y, Ando K, Sasaki Y (2001) Monitoring acoustic emission from Finger-joints from tropical African hardwood for predicting ultimate tensile strength. Holzforschung 55, pp. 652-660

Byeon H. S., Fushitani M, Shimada M, Sato K (1992) Effects of stress concentration on the bending strength properties and acoustic emission of laminated wood beams having butt joints. Mokuzai Gakkaishi 38 (4), pp. 357-363

Yoshimura N, Shimotsu M, Honjou K, Kotaki M, Ogasawara Y (1987) Detection of starved joints in plywood by acoustic emissions (in Japanese). Mokuzai Gakkaishi 33 (8), pp. 650-653

Xu Y, Okumura S, Noguchi M (1993) Thermographic detection of starved joints of wood (in Japanese). Mokuzai Gakkaishi 39 (5), pp. 544-549 